\title{
Perinatal outcome of preterm labour with and without prelabour rupture of membranes - an observational study
}

\author{
Keya Chatterjee, Aloke Kumar De, Aparna Chakraborty
}

\author{
Corresponding author: Dr. Aparna Chakraborty, Assistant Professor, West Bengal university of \\ Health Sciences, Dept. of Obst \& Gynae, RG Kar Medical College, Kolkata, India; \\ Email : apuam@rediffmail.com
}

Distributed under Attribution-Non Commercial - Share Alike 4.0 International (CC BY-NC-SA 4.0)

\begin{abstract}
Objective - This study was done with the mindset to identify preventable risk factor for preterm labor and develop optimum management protocol to achieve, lesser maternal and perinatal morbidity and mortality by observing mother with preterm labour. Method - In this study 100 antenatal women admitted with preterm labour with gestational age more than 28 completed weeks to less than 37 completed weeks were observed till delivery. Maternal and fetal outcome were analyzed and measures that could reduce perinatal morbidity and mortality were identified. Results All the women with preterm labour had presented with PROM too. Maternal outcome, perinatal morbidity and mortality all showed close relation with the duration of rupture of membranes, with $39.28 \%$ of mother with more than 36 hours since rupture of membranes had greater perinatal morbidity. Those babies with gestational age between 2832 weeks had perinatal morbidity in $51.43 \%$ cases and mortality was $34.29 \%$. Subclinical urogenital infection was present in most of the mothers with $12 \%$ of them having febrile morbidity. Cervical swab was positive in $23 \%$ of the cases with 10 cases of normal vaginal flora and 4 cases of E. coli. Hyperbilirubinemia and RDS both having incidence of $29.60 \%$ followed by sepsis with incidence of $14 \%$ were responsible for most of the perinatal morbidity and mortality. Conclusion - A gestational age approach to therapy is found important. Perinatal mortality and morbidity was not influenced by the mode of delivery. As the duration of PPROM increased, perinatal morbidity and mortality also increased.
\end{abstract}

Keywords: Preterm labor, premature rupture of membranes.

The normal development, structural integrity and function of the foetal membranes are essential for the normal progress and outcome of pregnancy. One of the most important function of the membranes is to remain intact until the onset of labour at term in order to maintain the protective intrauterine fluid environment; the amniotic fluid upon which foetus depends for its survival in utero. Preterm birth is defined as birth prior to 37 weeks of gestation, and preterm premature rupture of membrane (PPROM) is defined as the spontaneous rupture of amniotic membrane with release of amniotic fluid after 28 weeks but before 37 weeks of gestation.

Preterm labour is the presence of regular uterine contractions that leads to progressive changes in the cervix prior to 37 completed weeks of gestation, threatening premature delivery of fetus. In most pregnancies labour begins at term in the presence of intact foetal membranes. Without intervention their spontaneous rupture usually occurs near the end of the first stage of labour. The onset of labour following premature rupture of membrane (PROM) is directly related to gestational age at the time of rupture. After 36 weeks more than $80 \%$ of patients will be in labour within 24 hours; before 28 weeks only $48 \%$ will be in labour within 3 days of rupture. Preterm birth, affects $18 \%$ of all pregnancies. It is the leading cause of neonatal death and the second most cause of childhood death below the age of 5

Received: $25^{\text {th }}$ June 2020, Peer review completed: $15^{\text {th }}$ November 2020, Accepted: $5^{\text {th }}$ December 2020.

Chatterjee K, De AK, Chakraborty A. Perinatal outcome of preterm labour with and without prelabour rupture of membranes - an observational study. The New Indian Journal of OBGYN. 2021; 8(1): 89-94. 
years ${ }^{1}$. The single greatest risk factor for preterm delivery is a history of preterm labour, so delivery cannot be reliably predicted in first pregnancy. The risk of preterm delivery after one and two previous preterm deliveries has been given as $15 \%$ and $41 \%$ respectively ${ }^{2}$. Neonates born preterm are at an increased risk of short term complications attributed to immaturity of multiple organ systems, as well as neurodevelopmental disorders, such as cerebral palsy, intellectual disabilities, and vision/hearing impairments ${ }^{3}$. A positive swab for fetal fibronectin taken in the late second or early third trimester increases the likelihood of preterm delivery by a factor of 4.2 and a negative swab reduces the likelihood of delivery to 0.78 are seen from a meta-analysis including women both at high and low risk ${ }^{4}$. A study where testing was restricted to women with high risk at 24 weeks has shown a likelihood ratio of 11.8 and 0.48 for a positive test and negative test respectively ${ }^{5}$. Hence fetal fibronectin can be a helpful indicator for subsequent preterm delivery.

Several biochemical and biophysical markers have been proposed for the identification of patients at risk for spontaneous preterm delivery, in both patients with threatened preterm labor and asymptomatic ones, with the hope that interventions could prevent preterm delivery ${ }^{6-8}$. There is now evidence that examination of the cervix with ultrasound is superior to vaginal digital examination ${ }^{9}$ and in patients presenting with preterm labor can assist in determining the risk for preterm delivery before 34 weeks. In general, the shorter the cervix, the higher the risk for preterm delivery and vice versa ${ }^{10.11}$. Transvaginal cervical sonography is a good method to assess the risk of preterm delivery in patients presenting with preterm labor, low risk asymptomatic patients and patients at high risk for preterm delivery. In patients with a long cervical length $(4.3 \mathrm{~cm})$, the likelihood of preterm delivery is low and, therefore, avoiding aggressive intervention in the setting of premature labor may be justified ${ }^{12}$. Patients who have a short cervix would have a higher rate of preterm delivery and may benefit from targeted interventions (i.e. steroid administration and transfer to a centre with a newborn special intensive care unit ${ }^{13}$. A cervical length of $25 \mathrm{~mm}$ or less had a sensitivity, specificity, positive predictive value, and negative predictive value of $76 \%, 68 \%, 20 \%$, and $96 \%$, respectively ${ }^{14}$.

Rupture of membrane is usually followed by labour. The onset of labour is directly related to the gestational age at the time of rupture. PPROM is an obstetric conundrum which is poorly defined, with an obscure aetiology and is associated with significant maternal and neonatal morbidity and mortality and has diverse and controversial management strategies.

\section{Materials and methods}

The present cross sectional analytical study was done in department of obstetrics and gynaecology, R G Kar Medical College and Hospital from July 2018 to June 2019. The study population included antenatal women admitted with preterm labour with gestational age more than 28 completed weeks to less than 37 completed weeks. Mothers who met the inclusion and exclusion criteria of the study, in the study period were considered as the study participants. There were total 100 mothers.

Inclusion criterias: 1) Antenatal women admitted with preterm labour with gestational age more than 28 completed weeks to less than 37 completed weeks with live fetus, 2) Regular uterine contractions of one or $>$ one/10 minute, 3) Progressive changes in cervix in the form of effacement or dilatation, 4) With or without rupture of membranes, 5) Singleton pregnancy, 6) Clear liquor.

Exclusion criterias: 1) Gestational age less than 28 completed weeks or more than 37 completed weeks, 2) Induction of labour before 37 completed weeks for maternal or foetal indications, 3) Intrauterine foetal demise, 4) Congenital anomalies of the foetus, 5) Multiple pregnancy, 6) Meconium stained liquor.

A detailed history including age, booking, socioeconomic status, time of onset of draining, amount of fluid lost, its colour, association with pain or bleeding per vagina and perception of foetal movements was taken for women admitted with preterm labour and satisfying the study criteria. After general and systemic examination, following were noted - height of uterine fundus, lie, presentation and position of foetus, engagement of presenting part, condition of uterus whether contracted or relaxed. Foetal heart sound was auscultated and its rate and rhythm were noted. A sterile speculum examination was done to identify any amniotic fluid pooling in the vaginal fornix. The colour and smell of fluid was noted if dribbling seen. If no fluid was seen, the patient was asked to cough and drainage of fluid was looked for. In doubt, vaginal fluid specimen was collected and subjected to litmus paper test. Cervical swab was taken and sent for gram stain and culture sensitivity. A single pelvic examination was done to diagnose preterm labor. Investigations like total count, differential count and $\mathrm{C}$ reactive protein (CRP) were done. Prophylactic antibiotic in the form of injection ampicillin 1 gm IV every 6 hourly was given. 
Depending upon the gestational age and Bishop's score labour was augmented with oxytocin or prostaglandin, if needed. Progress of labour was monitored, PPROM to delivery interval were noted. Maternal pulse, blood pressure, foetal heart rate and its variations were checked frequently. The onset of any complications like foetal distress, foetal heart rate variations, chorioamnionitis (clinical) were looked for. Progress of labour was monitored. If there was any evidence of foetal jeopardy or any other obstetrical complications, labour was cut short by instrumental delivery or caesarean section as required. Following facts were noted soon after delivery - Apgar score at 1 and 5 minutes, birth weight, congenital anomalies, immediate complications and birth injuries, signs of asphyxia, meconium aspiration, sepsis. The babies were followed up in the postnatal period. Neonatal morbidity and mortality were noted. Mothers were watched for third stage complications like postpartum haemorrhage and retained placenta and were followed up in puerperal period. Women were specifically asked for foul smelling lochia and the presence of febrile morbidity. Episiotomy wound and caesarean section wound were observed and regular follow-up was done. Maternal morbidity like puerperal sepsis, urinary and respiratory tract infection and wound infection were looked for. Both mother and the baby were followed up till their stay in the hospital.

Variables like age, parity, duration of pregnancy, and mode of delivery, maternal and foetal condition are recorded. All relevant data are compiled and entered into computer using computer based software SPSS for appropriate analysis. Quantitative variable like maternal age, gestational age, and Bishop score are presented by mean \pm standard deviation. Frequency and percentage are computed for presentation of parity, cervical ripening, mode of delivery, induction to delivery interval and maternal complications. Quantitative data analyzed by proportion and Chi square test at $\mathrm{p}<0.05$ level of significance.

\section{Results}

Study shows that highest number of PPROM cases were in the age group of 20-29 years. PPROM was present in 61\% of mother in the age group of 20-29 years. No specific weeks of gestation seen as separately vulnerable for preterm labour (table-1).

Patients from low socioeconomic status were $58 \%$ and middle socioeconomic status were $30 \%$. This is true for both PPROM and PTL. Patients who had 3 antenatal checkups of which at least one in third trimester were considered booked. Study had $16 \%$ booked cases and unbooked cases of $84 \%$. Numbers of primigravida in the study were $48 \%$ and multigravida were $52 \%$.

Table 1: Analysis of PPROM and preterm delivery cases according to maternal age and gestational age.

\begin{tabular}{llll}
\hline Gestational age & $\begin{array}{l}\text { Less than 20 yrs } \\
\text { No }(\%)\end{array}$ & $\begin{array}{l}\text { 20-29yrs } \\
\text { No }(\%)\end{array}$ & $\begin{array}{l}\text { 30 or more } \\
\text { No }(\%)\end{array}$ \\
\hline $28-32$ wks & $6(17.14 \%)$ & $23(65-71 \%)$ & $6(17.14 \%)$ \\
$33-35$ wks & $8(25 \%)$ & $18(56.25 \%)$ & $6(18.75 \%)$ \\
36 or more & $10(33.33 \%)$ & $20(66.66 \%)$ & $3(9.09 \%)$ \\
\hline \multicolumn{4}{l}{ PPROM - Preterm premature rupture of membrane } \\
\hline
\end{tabular}

PPROM - Preterm premature rupture of membrane

Spontaneous vaginal deliveries were in $45 \%$ of the cases and augmentation was done in $55 \%$ of the cases. PPROM is often followed by labour and the onset of labour after PPROM is directly related to the gestational age at the time of rupture. In this study $45 \%$ developed spontaneous labour and 55\% needed augmentation (table - 2).

Table 2: Analysis of PTL with PPROM according to mode of delivery.

\begin{tabular}{lll} 
Mode of delivery & No of cases & Percentage \\
\hline Spontaneous labor & 45 & 45 \\
Induction of labor & 13 & 13 \\
Augmentation of labor & 28 & 28 \\
Induction and augmentation & 14 & 14 \\
\hline
\end{tabular}

Maximum number of LSCS (38\%) were seen in the group with bishop score $0-5$, comparable with the mode of delivery in general population delivered in our hospital (Normal delivery $-62.7 \%$, LSCS $-26.2 \%$ and outlet forceps - $11.1 \%)$. LSCS were more when augmentation of labour was done, compared to cases with Bishop score $>5$. Malpresentation and foetal distress due to oligohydramnios also resulted in LSCS. Cases with unfavourable cervix were better off with a wait and watch policy for $24-48$ hours period. Prostaglandins offered a considerable benefit in these cases with local PGE2 gel used to ripen the cervix followed Table 3: Analysis of PPROM according to Bishop score at the time of admission and

\begin{tabular}{llllll}
$\begin{array}{l}\text { Bishop } \\
\text { score }\end{array}$ & $\begin{array}{l}\text { Number } \\
\text { of cases }\end{array}$ & $\begin{array}{l}\text { Vaginal delivery without } \\
\text { forceps. No (\%) }\end{array}$ & $\begin{array}{l}\text { Outlet forceps } \\
\text { No (\%) }\end{array}$ & $\begin{array}{l}\text { LSCS } \\
\text { No (\%) }\end{array}$ & $\begin{array}{l}\text { P } \\
\text { value }\end{array}$ \\
\hline $0-5$ & 52 & $24(46 \%)$ & $8(15 \%)$ & $20(39 \%)$ & \\
$6-10$ & 42 & $35(83 \%)$ & $2(5 \%)$ & $5(12 \%)$ & 0.0015 \\
$11-13$ & 6 & $6(100 \%)$ & & & \\
\hline
\end{tabular}
by oxytocin supplementation, if required (table - 3).

No statistical significance is found between primigravida and multigravida when comparing mode of delivery. $25 \%$ cases had caesarean delivery of which $68 \%$ percentage were in the multigravida, with $\mathrm{p}$-value 0.176 which is statistically insignificant.

Augmentation was done in 55 cases of which $78 \%$ delivered within 12 hours, $16 \%$ delivered in 24 hours and 5\% after 24 hours, with the advantage of shorter maternal hospital stay and less chorioamnionitis, shorter neonatal hospital stay and less neonatal sepsis (28\% vs $60 \%)$ 
The New Indian Journal of OBGYN. 2021 (July-December);8(1)

(table - 4). There was no difference in the rates of LSCS, postpartum infection and neonatal survival.

Table 4: Analysis of PTL with PPROM according to induction to delivery interval $(\mathrm{N}=\mathbf{5 5})$

\begin{tabular}{lll}
\hline Induction to delivery interval & No of cases & $\mathbf{\%}$ \\
\hline Less than $12 \mathrm{hrs}$ & 43 & $78.18 \%$ \\
$13-24 \mathrm{hrs}$ & 9 & $16.36 \%$ \\
$25-48 \mathrm{hrs}$ & 2 & $3.36 \%$ \\
More than $48 \mathrm{hrs}$ & 1 & $1.83 \%$ \\
\hline
\end{tabular}

Most common maternal complication was subclinical urogenital infection (53\%) followed by oligohydramnios $(25 \%)$ and $13.5 \%$ women presented with chorioamnionitis. The main indication for LSCS was malpresentation (28\%) followed by foetal distress (24\%), failure of progress of labour (12\%) and transverse lie (8\%).

Table 5: Analysis of PPROM according to investigations for evidence of infection

\begin{tabular}{lll}
\hline Investigations & No of cases & $\mathbf{\%}$ \\
\hline Cervical swab positive & 23 & 23 \\
CRP Positive & 19 & 19 \\
WBC more than 12000 & 38 & 38 \\
\hline
\end{tabular}

Cervical swab was positive in $23 \%$ of the cases with 10 cases of normal vaginal flora, 4 cases of E. Coli, 2 cases of Klebsiella, 2 cases of group B Streptococcus, 1 case of Staphylococcus aureus, 1 case of coagulase negative Staphylococcus, 1 case of coagulase positive Staphylococcus and 2 cases of Candida species. The investigations like total count, C-reactive protein and high vaginal swab for culture and sensitivity were done to evaluate for the evidence of infection (table - 5). As leucocytosis can be affected by pregnancy and labour, CRP estimates seemed to be reliable monitoring tool. In this study the organisms isolated were E. Coli, coagulase positive staphylococcus, providential organisms, Candida and normal vaginal flora. Due to the limited culture and sensitivity facilities in our institute we did not find any anaerobic organisms in our study. As the duration of PPROM increased the maternal morbidity also increased.

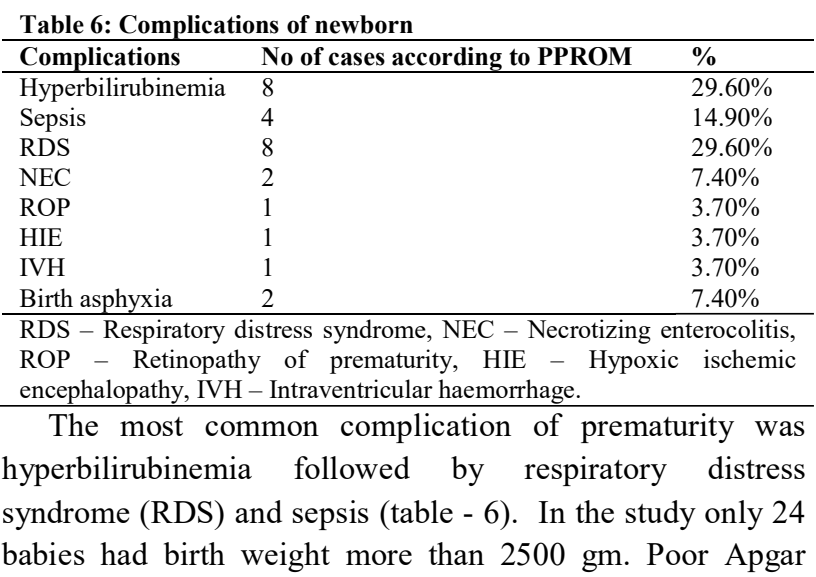

score seen mostly in 28-32 wks and below $1 \mathrm{~kg}$ weight, but the score increased with increase in the gestational age and birth weight of baby. Highest percentage of perinatal morbidity $(55.56 \%)$, and perinatal mortality $(86.67 \%)$ was seen between Apgar score 1 to 5 . In our study, perinatal mortality was $15 \%$ of which $26.6 \%$ were due to sepsis, $53.3 \%$ were due to RDS and $20 \%$ were due to birth asphyxia. Table 7: Analysis of perinatal morbidity and mortality in relation to duration of PPROM and gestational age

\begin{tabular}{llll}
$\begin{array}{l}\text { Duration of } \\
\text { PPROM }\end{array}$ & $\begin{array}{l}\text { No of } \\
\text { cases }\end{array}$ & $\begin{array}{l}\text { Perinatal } \\
\text { morbidity No(\%) }\end{array}$ & $\begin{array}{l}\text { Perinatal mortality } \\
\text { No (\%) }\end{array}$ \\
\hline Less than $12 \mathrm{hrs}$ & 29 & $3(10.34 \%)$ & $1(3.44 \%)$ \\
$12-24 \mathrm{hrs}$ & 19 & $7(36.84 \%)$ & $1(5.26 \%)$ \\
$24-36 \mathrm{hrs}$ & 24 & $6(25 \%)$ & $5(20.83 \%)$ \\
More than $36 \mathrm{hrs}$ & 28 & $11(39.28 \%)$ & $8(28.58 \%)$ \\
\hline Gestational & No of & Perinatal & Perinatal \\
age & cases & morbidity & mortality \\
\hline 28-32wks & 35 & $18(51.43 \%)$ & $12(34.29 \%)$ \\
$33-35 \mathrm{wks}$ & 32 & $7(21.87 \%)$ & $2(6.25 \%)$ \\
$36-37$ wks & 33 & $2(6.06 \%)$ & \\
\hline
\end{tabular}

As the duration of PPROM increased, perinatal morbidity and mortality also increased. Perinatal morbidity was $39.28 \%$ and perinatal mortality was $28.57 \%$ with PPROM to delivery interval more than 36 hours. As the gestational age increased, perinatal morbidity and mortality decreased. Perinatal morbidity was $51.43 \%$ and perinatal mortality was $34.29 \%$ with gestational age between 28 to 32 weeks (table-7).

\section{Discussion}

In the present study all the women with preterm labour had presented with PROM too. So perinatal outcome was not complicated with preterm labour (PTL) only, but PROM was also implicated with adverse outcome. Prevalence of PPROM is $7.72 \%$ in our centre. In our study highest number $(61 \%)$ of PPROM cases were observed in the age group of 20-29 years and comparatively less in both the extremes of age as observed by Okeye et al ${ }^{15}$ in his study. Also most of them belonged to lower socioeconomic status as found with other studies eg. Swathi Pandey et al suggesting that lower socioeconomic factor has a contributory role in the occurrence of preterm labour. Study found a higher percentage $(84 \%)$ of unbooked cases as compared to previous other studies eg. Anjana Devi et al ${ }^{16}$ had 52\% unbooked cases. Lack of antenatal care led to failure of identification of recurrent risk factors like PPROM or preterm delivery in previous pregnancy, induced abortions and any previous cervical surgery. Study did not find any difference in the parity of mother, as both primi and multipara were equally found vulnerable to preterm labour, also seen in other studies eg. Swathi Pandey (multipara 48\% and primipara 52\%) and Fatemeh Tavassoli ${ }^{17}$ (primipara 
$55.9 \%$ and multipara $44.1 \%$ ). Spontaneous vaginal deliveries were in $45 \%$ of the cases and augmentation was done in $55 \%$ of the cases, comparable to that of Kadikar et $\mathrm{al}^{18}$ where $79.19 \%$ of the patients required induction.

We had $25 \%$ of mother who needed cesarean delivery and these were mostly in mothers whose labour were augmented and had bishop score between 0-5. This number is comparable with other studies also eg. Kadikaret al, Trinity et al ${ }^{19}$ and Shelha Noor et $\mathrm{al}^{20}$. It was seen that mother whose labour was augmented had less duration of hospital stay and so less morbidity both in respect to herself and her neonate. And this finding was also supported by a study by Mercer ${ }^{21}$ that intentional delivery reduces the length of maternal hospitalization along with reduction of infection in both mother and the new born.

Most common maternal complication was subclinical urogenital infection. Indication for cesarean delivery were malpresentation, foetal distress, failure of progress of labour and transverse lie in descending order, comparable to study by Kamala Jayaram, though percentage of cesarean delivery was higher in a study by Singhal at $49 \%$ with fetal distress being the main indication. The study of cervical swab found E. Coli to be the main pathogen comparable to the studies by Swathi Pandey and Kamala Jayaram. Our study also confirmed that as the duration of rupture of membranes increased the morbidities also increased as also shown by other studies.

Study by Arul Kumaran ${ }^{22}$ showed that after 32 weeks of gestation the common causes of perinatal morbidity were RDS, perinatal asphyxia and infection. We had hyperbilirubinemia as the most common neonatal morbidity followed by RDS and sepsis. As with all other studies our study also revealed that more the gestational age better is the neonatal prognosis. The study by Russel ${ }^{23}$ showed that the danger of infection to both mother and foetus increases with duration of PPROM. But prolongation of latent period decreases the incidence of RDS.

Limitations: 1) This is an observational study, which may encompass some missing data, 2) The data were collected just from one hospital which too may not be representative of all maternity hospitals in India, 3) The sample size was small and should be increased in further studies.

\section{Conclusion}

Management of preterm labour is not a generalised regime. Multi factorial study of individual cases and hence management has to be planned accordingly, varying from expectant to aggressive therapy. Prevention of preterm birth by identifying the high risk group among mothers by sonographic measurement of cervical length at 18 weeks gestational age during anomaly scan can be achieved by taking appropriate preventive measures. Though successful prevention of preterm labour requires a multifaceted approach. Combining educational programs, lifestyle modification, nutritional supplementation and optimization of obstetric healthcare is important in reducing perinatal morbidity and mortality. From this study, PPROM seems to be an important risk factor for preterm labour, and as it is a modifiable factor in many cases, hence taking care of those aspects will help to prevent preterm labour to large extent.

\section{Conflict of interest: None. Disclaimer: Nil.}

\section{References}

1. Caughey AB, Robinson JN, Norwitz ER. Contemporary Diagnosis and Management of Preterm Premature Rupture of Membranes. Rev. Obstet Gynecol. 2008; 1(1): 11-22.

2. Mercer BM, Goldenberg RL, Das A. The preterm prediction study; a clinical risk assessment system. Am j Obstet Gynecol. 1996;174: 1885-93.

3. Pandey S, Dave A, Bandi S. Maternal and fetal outcome in cases of preterm premature rupture of membranes. Journal of obstetrics and Gynaecology of India. 2000; 50: $63-5$.

4. Honest H, Bachmann JM, Gupta JK. Accuracy of cervicovaginal fetal fibronectin in predicting the risk of spontaneous preterm birth; systematic review. BMJ. 2002; 325: 301-11.

5. Shennan A, Jones G, Hawken J. Fetal fibronectin test predicts delivery before 30 weeks of gestation in high risk women, but increases anxiety. Br J Obstet Gynecol. 2005; 112: 293-8.

6. Honest H, Forbes CA, Dure'e KH, Norman G, Duffy SB, Tsourapas A, et al. Screening to prevent spontaneous preterm birth: systematic reviews of accuracy and effectiveness literature with economic modeling. Health Technol Assess. 2009;13: 1- 627.

7. Lamont RF. Setting up a preterm prevention clinic: a practical guide. BJOG. 2006; 113(Suppl 3): 86-92

8. Lockwood CJ, Senyei AE, Dische MR, Casal D, Shah $\mathrm{KD}$, Thung SN, et al. Fetal fibronectin in cervical and vaginal secretions defines a patient population at high risk for preterm delivery. N Engl J Med. 1991; 325: 669-74. 
9. Gomez R, Galasso M, Romero R, Mazor M, Sorokin Y, Treadwell M, et al. Ultrasonographic examination of the uterine cervix is better than cervical digital examination as a predictor of the likelihood of premature delivery in patients with preterm labor and intact membranes. Am J Obstet Gynecol. 1994; 171: 956-64.

10. Berghella V, Hayes E, Visintine J, Baxter JK. Fetal fibronectin testing for reducing the risk of preterm birth. Cochrane Database Syst Rev. 2008 Oct 8; 4: CD006843.

11. Da Fonseca EB, Celik E, Parra M, Singh M, Nicolaides KH. Progesterone and the risk of preterm birth among women with a short cervix. N Engl J Med. 2007; 357: 462-9.

12. Espinoza J, Romero R, Goncalvez LF, Kusanovic JP, Nien JK. Assessment of risk for preterm birth in aymptomatic patients and those with preterm labor. Textbook for the perinatal medicine. Taylor and Francis: Oxford, UK; 2006. pp. 1417-30.

13. Di Renzo GC. The great obstetrical syndromes. J Matern Fetal Neonatal Med. 2009; 22: 633-5.

14. Mella MT, Berghella V. Prediction of preterm birth: cervical sonography. Semin Perinatol. 2009; 33: 317-24.

15. Okeke TC, Enwereji JO, Okoro OS, Adiri CO, Ezugwu $\mathrm{EC}$, Agu PU, et al. The Incidence and Management Outcome of Preterm Premature Rupture of Membranes in a Tertiary Hospital in Nigeria. American Journal of Clinical Medicine Research. 2014; 1: 14-17.

16. Devi A, Rani R. Premature rupture of membranes - A clinical study. Journal of Obstet and Gynaecol of India. 1996; 8: 46-63.
17. Tavassoli F. Survey of pregnancy outcome in preterm premature rupture of membrane in AFI $<5$ and $>5$. OMJ. 2010; 25: 118-23.

18. Kadikar GK, Gandhi MR, Damani SR. A Study of FetoMaternal Outcome in Cases of Premature Rupture Of Membrane. IJSR March 2014; 3(3): 299-301.

19. Triniti A. Epidemiologic study of cervical swab culture in preterm premature rupture of membrane at Ramathibodi Hospital. Thai Journal of Obstetrics and Gynaecology. 2008; 16: 17861-67.

20. Noor S, Ali F Hasan S, Ruqqia S, Rubina B. Foetomaternal outcome in patients with or without premature rupture of membrane. J Ayub Med Coll Adottabad. 2010; 22(1): 164-7.

21. Mercer BM, Arheart KL. Antimicrobial therapy in the expectant management of PPROM. Lancet. 1995; 346: 1271-9.

22. Kumaran A, Penna LK. Prelabor ROM Management of labor. Orient Longman: London; 2005; pp.306-18.

23. Russell KP, Anderson G. Aggressive management ruptured membranes. Am J Obstet Gynecol. 1962; 83: 1930-62.

\section{Keya Chatterjee ${ }^{1}$, Aloke Kumar $\mathrm{De}^{2}$, Aparna Chakraborty $^{3}$}

${ }^{1}$ Final year Postgraduate Trainee, West Bengal university of Health Sciences, India; ${ }^{2}$ Associate Professor, Calcutta University, India; ${ }^{3}$ Assistant Professor, West Bengal university of Health Sciences, Dept. of Obst \& Gynae, RG Kar Medical College, Kolkata, India. 